\title{
Silane Crosslinked Polyethylene from Different Commercial PE's: Influence of Comonomer, Catalyst Type and Evaluation of HLPB as Crosslinking Coagent
}

\author{
Renato Pereira de Melo ${ }^{a}$, Vinícius de Oliveira Aguiar ${ }^{a}$, Maria de Fátima Vieira Marques ${ }^{a *}$ \\ ${ }^{a}$ Instituto de Macromoleculas Professora Eloisa Mano, Universidade Federal do Rio de Janeiro - UFRJ, \\ Av. Horácio Macedo, s/n, CEP 21941-598, Rio de Janeiro, RJ, Brazil
}

Received: June 16, 2014; Revised: February 4, 2015

\begin{abstract}
In the present work, the synthetic route to obtain crosslinked polyethylene (PEX) was studied using vinyltrimethoxy silane (VTMS) as crosslink agent and commercial polyethylene (HDPE and LLDPE). Materials were processed with increasing amounts of VTMS (2.5, 5.0 and $7.5 \mathrm{wt} . \%)$. After insertion of silane onto polymer chain in solid state, samples were molded by compression. Gel content was used to measure the extension of crosslinking. Melting temperature and degree of crystallinity were evaluated using differential scanning calorimetry (DSC). The microstructure of the starting polyethylene was correlated with the effectiveness of crosslinking and the resultant thermal and mechanical properties of the PEX. Hydroxylated liquid polybutadiene (HLPB) was employed to improve crosslink efficiency, as well as mechanical properties of the material.
\end{abstract}

Keywords: crosslinking, structure, crystallization, additives

\section{Introduction}

The linking of linear polymer chains by covalent bonds produces a tridimensional network. Lightly crosslinked polymers possess only occasional crosslinks, but these prevent the material deforming indefinitely under load. Between the crosslinks, the molecular segments remain flexible. Thus, at appropriate temperature, the polymer may be rubbery or rigid; it may also crystallize if the segments can pack together sufficiently closely. As the degree of crosslink increases, segmental motion is progressively restricted until in, for example, phenolic, amino or epoxy resins, only infusible, rigid, amorphous state exists ${ }^{1-3}$.

Polyethylene crosslinking may be induced through three different methods: radiation, peroxide and silane ${ }^{4-8}$. In peroxide crosslinking, organic peroxide and polyethylene are blended during extrusion process and free radicals are formed, crosslinking the polymer chain to produce a network during thermal decomposition ${ }^{9}$. One of the most usual substances to crosslink polyethylene is dicumyl peroxide (DCP), moderately stable in low-density polyethylene at a temperature range between $130-150{ }^{\circ} \mathrm{C}$. Generation of primary radicals, attack of these radicals in the polymeric chain by hydrogen capture and combination of two polymeric radicals to form a carbon - carbon bond are showed in Figure $1^{10-12}$. However, this crosslinking technique involves high costs. Moreover, there are risks of pre-curing during peroxide crosslinking ${ }^{13,14}$.

Silane crosslinking is defined by grafting of vinyltriethoxysilane (VTES) or vinyltrimethoxysilane (VTMS) in polyethylene with small amounts of peroxides as initiators, followed by hydrolysis and condensation reaction of generated silanol groups ${ }^{15}$. Crosslinking takes place between

*e-mail: fmarques@ima.ufrj.br these silanol groups, forming siloxane structure (-Si-O-Si-) with water loss. This reaction is optimized with presence of organotin components as dibutyltin dilaurate (DBTDL), according to Figure $2^{16}$. The influence of some parameters on the molecular structure of a polymer can lead to development of new products, which can be tailored according to some requirements. The creation of a crosslink network between individual polymer chains leads to restriction of chain movement. Hence, when heat or other form of energy is applied, the basic network structure cannot deform and some of the properties (e.g. dimensional stability, impact strength, creep and abrasion resistance) are retained at high temperatures. Those properties are important for the applications of wire and cable coating, hot water tubing and weathership ${ }^{17-19}$. The degree of silane crosslinking is of vital importance in determining how well the properties of the materials are maintained at elevated temperature ${ }^{20}$.

The aim of this work is to evaluate the synthesis of PEX obtained from different starting polyethylenes using VTMS, to compare the influence of PE microstructure on the gel content, and on thermal and mechanical properties of the final product. A new crosslinking coagent (hydroxylated liquid polybutadiene - HLPB) was also evaluated ${ }^{21}$.

\section{Experimental Procedure}

\subsection{Material}

Polyethylenes HDPE and LLDPE's were gently provided by Quattor S.A., Brazil and their characteristics are presented in Table 1. Dicumyl peroxide, DCP 98\%, and vinyltrimethoxy silane, VTMS 97\%, were acquired from Aldrich Co. Ltd., USA. Hydroxylated liquid polybutadiene (HLPB) was purchased from Petroflex Ltd., Brazil. Dibutyltin dilaurate 


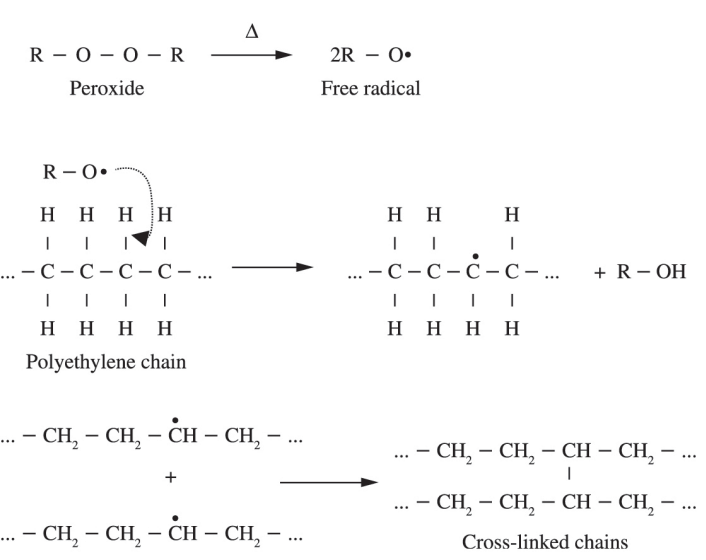

Figure 1. Scheme of the mechanism of peroxide polyethylene crosslinking ${ }^{11}$.

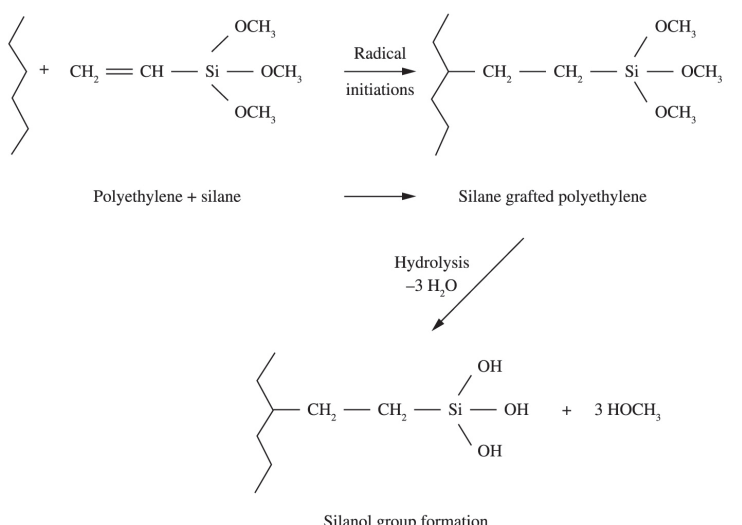

$\left\langle\begin{array}{cc}\mathrm{CH}_{2}-\mathrm{CH}_{2}-\mathrm{Si}_{\mathrm{OH}}^{\mathrm{OH}} & +\mathrm{OH} \\ \mathrm{HO}_{\mathrm{OH}} / \mathrm{Si}-\mathrm{CH}_{2}-\mathrm{CH}_{2}\end{array}\right\rangle$

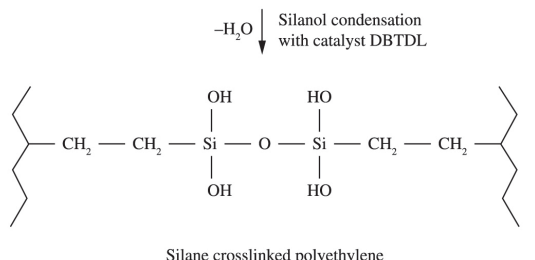

Silane crosslinked polyethylene

Figure 2. Scheme of the mechanism of silane polyethylene crosslinking ${ }^{16}$.

(DBTDL) was donated by Miracema-Nuodex Company, Brazil. All of these reagents were used as received.

\subsection{Crosslinking reactions}

At first, polyethylenes were milled using a knife mill model IKA-MF10 with rotation of $4000 \mathrm{rpm}$. Then, VMTS $(10.0 \% \mathrm{v} / \mathrm{v}), \mathrm{DCP}(1.0 \% \mathrm{v} / \mathrm{v})$ and DBTDL $(1.0 \% \mathrm{v} / \mathrm{v})$ were dissolved in methanol and, after this, were mixed with milled polymers, according to Table 1. For the samples with HLPB, it was introduced with pure polyethylene and subsequently, solutions were added. Finally, samples were molded by compression at $180{ }^{\circ} \mathrm{C}$ and $10 \mathrm{MPa}$ for 30 minutes for the crosslinking reaction.

\subsection{Gel content}

Gel content of silane crosslinked materials after solvent extraction was calculated according to standard ASTM D2765-01. Nearly $0.5 \mathrm{~g}$ of each sample was extracted in refluxing xylene for $6 \mathrm{~h}$. After extraction, samples were weighted before and after drying in a vacuum oven at $60^{\circ} \mathrm{C}$ until constant weight. Equation 1 shows the calculation of gel content of crosslinked samples ${ }^{22}$.

$\%$ gel content $=[($ final weight of sample $) /$

( initial weight of sample) $] \times 100$

\subsection{DSC analysis and determination of degree of crystallinity}

Samples with masses range from 3.0 - $4.5 \mathrm{mg}$ were weighed in an aluminum holder and heated at a rate of $10^{\circ} \mathrm{C} / \mathrm{min}$ over a temperature range from $25-170{ }^{\circ} \mathrm{C}$ under nitrogen in a DSC-TA instrument, Q -1000. Degree of crystallinity was calculated using Equation 2:

$\mathrm{X}_{\mathrm{c}}=\frac{\Delta \mathrm{H}_{\mathrm{m}}^{\mathrm{a}}}{\Delta \mathrm{H}_{\mathrm{m}}^{100}}$

Where $\mathrm{X}_{\mathrm{c}}=$ degree of crystallinity $(\%) ; \Delta \mathrm{H}_{\mathrm{m}}^{\mathrm{a}}=$ melting enthalpy of the sample $(\mathrm{J} / \mathrm{g}) ; \Delta \mathrm{H}_{\mathrm{m}}^{100}=$ melting enthalpy of $100 \%$ crystalline polyethylene $(\mathrm{J} / \mathrm{g})$, which was considered to be $292 \mathrm{~J} / \mathrm{g}^{23}$.

\subsection{Thermogravimetric analysis}

The thermogravimetric analysis (TGA) was performed in heating mode from $25-700^{\circ} \mathrm{C}$ at $10^{\circ} \mathrm{C} / \mathrm{min}$ under nitrogen. Samples with approximately $10 \mathrm{mg}$ were weighted and initial temperature of degradation $\left(\mathrm{T}_{\text {onset }}\right)$, as well as maximum degradation rate $\left(\mathrm{T}_{\max }\right)$, was determined.

\subsection{Mechanical properties}

Tests were performed following ASTM D638-5 standard. Deformation of the specimens was fixed at $50.0 \mathrm{~mm} / \mathrm{min}$. Dimensions of test bars for tension analysis were approximately $6.0 \times 3.0 \times 1.2 \mathrm{~mm}$ (length $\times$ width $\times$ thickness $)$. For each sample, six specimens were evaluated for reproducibility of the results and standard deviations were calculated. The tensile and elongation at yield and at break were also obtained, as well as elasticity modulus.

\section{Results and Discussion}

After the crosslinking reactions of different LLDPE (obtained by Ziegler-Natta or metallocene catalysts) and HDPE with increasing amounts of silane, the samples were analyzed according to the gel content and the results are shown in Table 2 and Figure 3. It can be observed an increase of gel content with increasing of VTMS amount, as expected and also observed by some authors ${ }^{18,19,24}$. All samples have reached the maximum value of degree of crosslinking when VTMS concentration was 7.5 wt.\%. At low amounts of VTMS (2.5 wt.\%, samples LLDPE 1 (butene as comonomer) and LLDPE 2 (hexene as comonomer) showed similarly much higher degree of crosslinking compared with LLDPE 3 
Table 1. Characteristic of polyethylenes employed and conditions of crosslinking.

\begin{tabular}{|c|c|c|c|c|}
\hline Sample & Starting PE & $\begin{array}{l}\text { Original thermal } \\
\text { properties }\end{array}$ & VTMS (wt.\%) & Code \\
\hline \multirow{4}{*}{ LLDPE 1} & \multirow{4}{*}{$\begin{array}{c}\text { Ziegler-Natta, } 3.1 \mathrm{~mol} \% \\
\text { butene comonomer }\end{array}$} & \multirow{2}{*}{$\mathrm{T}_{\mathrm{m}}=121.9^{\circ} \mathrm{C}$} & 0 & BF0 \\
\hline & & & 2.5 & BFS2 \\
\hline & & \multirow{2}{*}{$X_{c}=41 \%$} & 5.0 & BFS5 \\
\hline & & & 7.5 & BFS7 \\
\hline \multirow{4}{*}{ LLDPE 2} & \multirow{4}{*}{$\begin{array}{c}\text { Ziegler-Natta, } 3.8 \text { mol\% } \\
\text { hexene comonomer }\end{array}$} & \multirow{2}{*}{$\mathrm{T}_{\mathrm{m}}=123.9^{\circ} \mathrm{C}$} & 0 & HF0 \\
\hline & & & 2.5 & HFS2 \\
\hline & & \multirow{2}{*}{$X_{c}=36 \%$} & 5.0 & HFS5 \\
\hline & & & 7.5 & HFS7 \\
\hline \multirow{4}{*}{ LLDPE 3} & \multirow{4}{*}{$\begin{array}{l}\text { Metallocene, } 1.7 \mathrm{~mol} \% \\
\text { hexene comonomer }\end{array}$} & \multirow{2}{*}{$\mathrm{T}_{\mathrm{m}}=119.5^{\circ} \mathrm{C}$} & 0 & MF0 \\
\hline & & & 2.5 & MFS2 \\
\hline & & \multirow{2}{*}{$X_{c}=57 \%$} & 5.0 & MFS5 \\
\hline & & & 7.5 & MFS7 \\
\hline \multirow{4}{*}{ HDPE } & \multirow{4}{*}{ Ziegler-Natta } & \multirow{2}{*}{$\mathrm{T}_{\mathrm{m}}=132.2^{\circ} \mathrm{C}$} & 0 & EI0 \\
\hline & & & 2.5 & EIS2 \\
\hline & & \multirow{2}{*}{$X_{c}=65 \%$} & 5.0 & EIS5 \\
\hline & & & 7.5 & EIS7 \\
\hline
\end{tabular}

VTMS - vinyltrimethoxy silane; PE mass = $2 \mathrm{~g}$; VTMS/DCP/DBTDL = 1/10/15; BF - butene comonomer ; HF - hexene comonomer ; MF - hexene comonomer (metallocene PE); EI - HDPE; 0 - no silane; S2 - 2,5 wt. \% of VTMS; S5 - 5,0wt. \% of VTMS; S7 - 7,5 wt. $\%$ of VTMS.

Table 2. Gel content and thermal properties of PEX samples.

\begin{tabular}{cccc}
\hline Sample & $\begin{array}{c}\text { Gel Content } \\
(\mathbf{\%})\end{array}$ & $\mathbf{X}_{\mathbf{c}}(\mathbf{\%})$ & $\mathbf{T}_{\mathbf{m}}\left({ }^{\circ} \mathbf{C}\right)$ \\
\hline BF0 & 0 & 46 & 121.9 \\
BFS2 & 61.7 & 34 & 119.0 \\
BFS5 & 70.7 & 34 & 117.0 \\
BFS7 & 83.7 & 33 & 113.1 \\
HF0 & 0 & 36 & 123.9 \\
HFS2 & 61.2 & 35 & 120.6 \\
HFS5 & 66.3 & 31 & 114.4 \\
HFS7 & 74.1 & 30 & 118.7 \\
MF0 & 0 & 57 & 119.5 \\
MFS2 & 9.1 & 44 & 118.4 \\
MFS5 & 53.8 & 40 & 116.3 \\
MFS7 & 60.1 & 45 & 118.1 \\
EI0 & 0 & 65 & 132.2 \\
EIS2 & 0.9 & 65 & 131.6 \\
EIS5 & 16.5 & 50 & 131.6 \\
EIS7 & 25.6 & 54 & 131.5 \\
\hline
\end{tabular}

$\mathrm{BF}$-butene comonomer; HF - hexene comonomer; $\mathrm{MF}$ - hexene comonomer (metallocene PE); EI - HDPE; 0 - no silane; S2 - 2,5 wt.\% of VTMS; S5 - 5,0 wt.\% of VTMS; S7 - 7,5 wt.\% of VTMS.

(produced with metallocene catalyst). This is probably because of the relatively higher amounts of extractable fractions of low molecular weight chains with high comonomer concentration, typical of the $\mathrm{ZN}$ copolymers, which favors the attack of peroxides, producing high crosslinking reactions. However, at higher VTMS amounts, gel content was higher for LLDPE 1 than LLDPE 2, despite LLDPE 1 shows higher degree of crystallinity.

To understand this behavior, the microstructure of both ZN-LLDPE, with similar amounts of different comonomers (3.1\% of butene for LLDPE 1 and $3.8 \%$ of hexene for LLDPE 2) was analyzed. The first LLDPE has slightly lower $T_{m}$

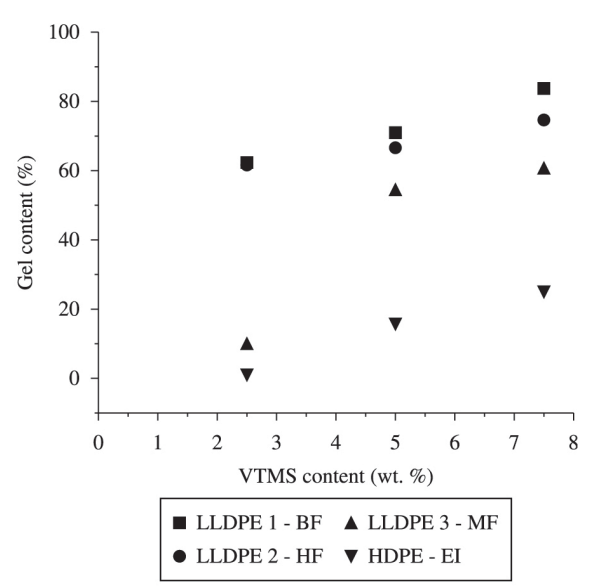

Figure 3. Gel content of crosslinked samples.

although much higher $\mathrm{X}_{\mathrm{c}}$ when compared with the second one. This is because of the size of comonomer and different sequence length distribution of monomers in the polymer chain. The introduction of hexene in the polyethylene chain in LLDPE2 will decrease sharply the degree of crystallinity of the polymer because of its bulkiness, although the distribution of monomers in the polymer chain is such that it leaves great length sequences of ethylene in the chain, and therefore $T_{m}$ is higher. Larger sequences of ethylene difficult the attack of peroxide and, as a consequence, lowers grafting reactions.

When density of polyethylenes are compared, it can be noted only a small increase of HDPE gel content, when compared to LLDPE's, reaching no more than 25.6\% at maximum VTMS concentration. According to Wong $\&$ Varrall $^{25}$, this behavior is due to the lack of tertiary carbons along HDPE chains. On the other hand, LLDPE 3 (from metallocene catalyst), considering only low density polyethylenes, showed less increase of gel content at the same silane concentration, $60.1 \mathrm{wt} \%$, i.e., more than twice 
of HDPE but less than the other LLDPE. So, it can be supposed that the chains of metallocene LLDPE are more able to be grafted by silane than those of HDPE because of the presence of tertiary carbons in its structure.

Other considerations must be taken according to the polymer microstructure. Metallocene polyethylene, due to the single-site nature of the catalyst, comprehends polymer chains with narrow molecular weight and interchain compositional distributions. This means that there is virtually any extractable fraction with low MW and high content of comonomer, and also any fraction containing chains with high sequences of ethylene (with low comonomer incorporation) as in the case of ZN-LLDPE, all polymer chains are very similar in length and composition. Therefore, a low amount of comonomer (such as $1.7 \%$ hexene) will deeply decrease the melting temperature, producing high amounts of small crystals (due to the lower sequences lengths of ethylene in the chain), which explains the characteristic of this polymer grade.

It is important also to consider that, as crosslinking process takes place in non-melt polymer and both LLDPE 3 and HDPE having high crystallinity index, maybe the water penetration was not favorable to hydrolysis of methoxy groups and condensation of hydroxyl groups to perform intermolecular crosslinking was hindered.

To compare crosslinking performance between metallocene LLDPE (MF) and Ziegler-Natta LLDPE's (BF and HF), it can be observed that, at lower VTMS content, crosslinking of Ziegler-Natta LLDPE's were higher than that of metallocene. Moreover, at $7.5 \mathrm{wt} \%$ of VTMS, where all polyethylenes reached higher gel content, metallocene LLDPE also showed low degree of crosslinking, almost $20 \%$ lower. This difference can be explained also by difference of crystallinity degree of polymers that is higher for metallocene LLDPE. Another reason can be attributed in terms of comonomer. According to Table 2, metallocene LLDPE has lower content of incorporated comonomer than Ziegler-Natta LLDPE's, which becomes difficult silane incorporation.

When crosslinked polymers synthesized by same catalyst (Ziegler-Natta) with similar comonomer content (butene and hexene) are compared, it can be noted that BF sample (LLDPE with butene) showed higher crosslinking degree than the one with hexene (HF sample), despite the higher crystallinity of pure LLDPE (BF0). As BF0 has less ethylene sequences length in chain, this can become favorable the attack of peroxide, as well as silane grafting reaction.

Crystallinity results of crosslinked samples are shown in Table 2 and Figure 4. In a general overview, increase of VTMS content leads to reduction of degree of crystallinity of silane-crosslinked samples. Curiously, lower variations of $\mathrm{X}_{\mathrm{c}}$ were attributed to Ziegler-Natta crosslinked samples (BF and HF). They showed less reduction until $7.5 \mathrm{wt} . \%$ of VTMS, which occurred because at higher VTMS amount, the gel content was elevated. Otherwise, to HDPE and mainly metallocene LLDPE, it can be observed higher variation in $\mathrm{X}_{\mathrm{c}}$, as well as gel content.

When melting temperature of crosslinked samples are analyzed, it can be seen in Table 2 and Figure 5, the decrease of melting temperature with increase of silane content. The same behavior was observed by Khonakdar et al. ${ }^{26}$. Crosslinked metallocene LLDPE (MF) and HDPE (EI)

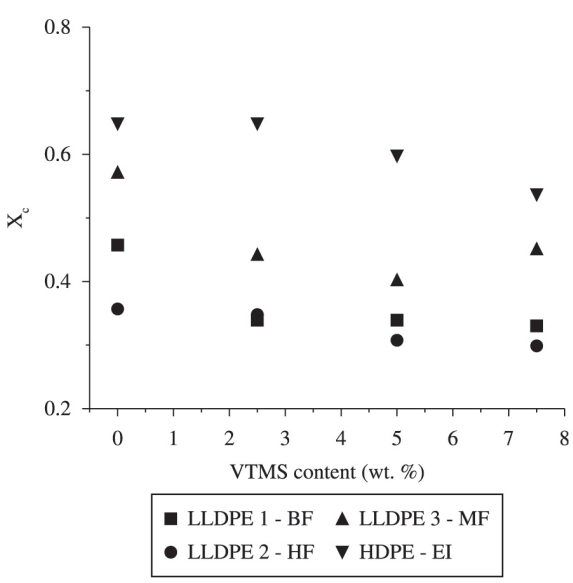

Figure 4. Degree of crystallinity of crosslinked samples.

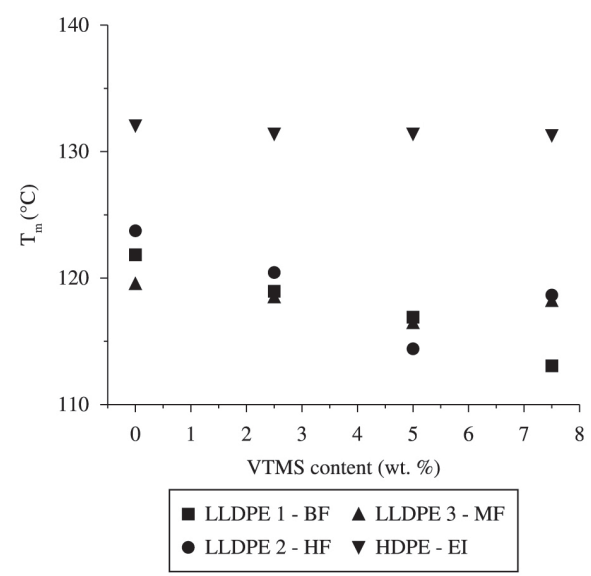

Figure 5. Melting temperature of crosslinked samples.

showed less significantly decrease in $\mathrm{T}_{\mathrm{m}}$ when compared with their correspondent pure samples. In HDPE, the low degree of crosslinking (gel content) explains this behavior. However, even with elevated degree of crosslinking (60\%), metallocene LLDPE still have long ethylene sequences that can crystallize. So, the crosslinking in this polymer is relatively more homogeneous.

Crosslinked Ziegler-Natta LLDPE's (BF and HF) showed higher decrease in melting temperature compared with other samples. Considering that grafting and subsequent formation of $\mathrm{Si}-\mathrm{O}-\mathrm{Si}$ bonds happens preferably in tertiary carbons, more present in Ziegler-Natta LLDPE's, it is more influent in crystal growth, becoming them more defective and decreasing the melting temperature.

In order to increase the properties of PEX, experiments using an auxiliary crosslinking agent were performed. The addition of hydroxylated liquid polybutadiene (HLPB) as a crosslink coagent was analyzed in samples which resulted in higher (BFS7) and lower (EIS7) gel content. Therefore, the crosslinking reaction was performed adding different contents of PBLH (5.0 and 10.0 wt.\%) at the same experiment conditions employed to compose those samples and variation of gel content was observed. 
To the Ziegler-Natta crosslinked sample (BFS7), it can be observed (Table 3 and Figure 6) that, with 5.0 wt.\% of HLPB incorporated in the formulation, gel content is slightly higher than crosslinked sample without HLPB $(89.1 \% \times 83.7 \%)$. No significant variation of gel content was noted when 10.0 wt. $\%$ of PBLH was added. The increase of gel content when HLPB is added can indicate that this coagent may increase silane grafting through diminishing the crystallinity, becoming easier water diffusion to form silanol groups, allowing higher condensation of these groups that can occur with grafted LLDPE chains, as well as HLPB grafted chains.

Table 3. Gel content of BFS7/HLPB and EIS7/HLPB samples.

\begin{tabular}{cc}
\hline \multicolumn{3}{c}{ Samples BFS7/HLPB } \\
\hline Sample & Gel Content (\%) \\
\hline BF0 & 0 \\
BFS7 & 83.7 \\
BPB1 & 80.6 \\
BPB5 & 89.1 \\
BPB10 & 88.5 \\
\hline \multicolumn{2}{c}{ Samples EIS7/HLPB } \\
EI0 & 0 \\
EIS7 & 25.6 \\
EPB5 & 60.0 \\
EPB10 & 76.5 \\
\hline
\end{tabular}

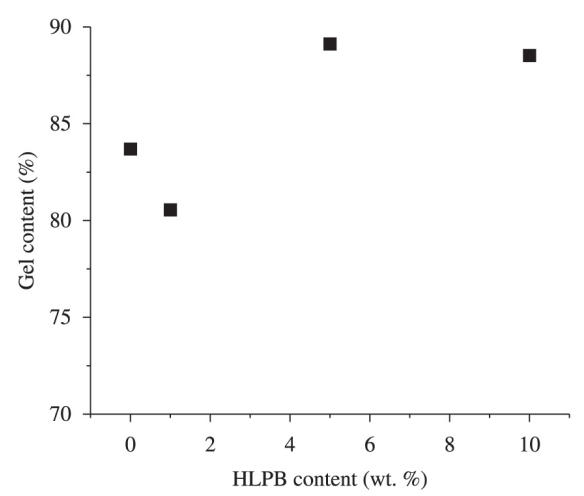

(a)

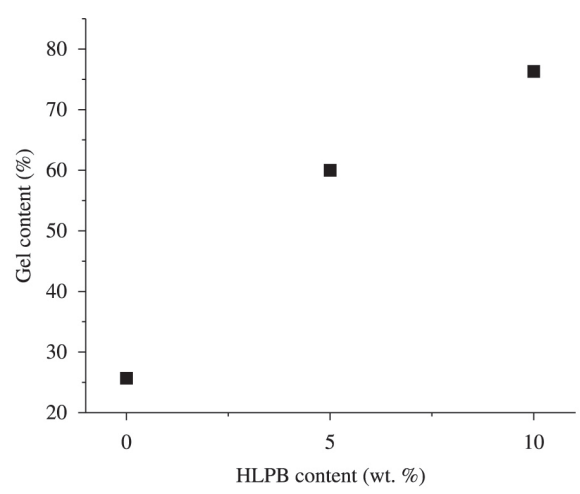

(b)

Figure 6. Gel content of samples: (a) BFS7/HLPB; (b) EIS7/HLPB.
Regarding to HDPE crosslinked samples (EIS7), according to the Table 3 and Figure 6, it can be noted a continuous increase of gel content. With $10.0 \mathrm{wt} \%$ of HLPB, the amount of gel is almost 3 times higher than crosslinked HDPE without HLPB. It can be supposed that with the coagent insertion being added at the same time with silane and catalyst, grafting of HLPB onto HDPE became easier as a consequence of the hydroxyl reactive groups of HLPB and also of the increasing distance between the linear chains, reducing crystallinity of grafted material. So, it is possible that water diffusion in the solid state was favored also, allowing the increase of gel content.

To evaluate mechanical properties of the final products, it was performed tension tests of pure Ziegler-Natta LLDPE (BF0), as well as crosslinked Ziegler-Natta LLDPE (BFS7 - higher gel content overall) and crosslinked BFS7 samples with 1.0, 5.0 and 10.0 wt.\% of HLPB. Results are shown in Table 4 and Figure 7. It can be observed an increase of elastic modulus compared to pure polymer ${ }^{27}$ and the decrease tendency when HLPB is inserted. Elongation at break tends to increase until $5.0 \mathrm{wt} . \%$ of HLPB in the PEX formulation. It can be noted also that elongation at yield did not change significantly, maybe because there is higher mobility and flexibility of chains and better plastic fluency once that possibly some extensions of chains did not crosslink.

Considering the low influence of crosslinking reactions on degree of crystallinity in LLDPE and crosslinking taking place in solid state, in fact it is expected reasonable distribution of $\mathrm{Si}-\mathrm{O}-\mathrm{Si}$ bonds across grafted polymer chain and, therefore, elastic modulus of crosslinked LLDPE would be higher than pure LLDPE. However, incorporation of HLPB at low concentration (1.0 wt.\%) led to decrease of modulus and with further increase to 5.0 and $10.0 \mathrm{wt} \%$, there was an increase of this property. The increase of functional $\mathrm{OH}$ groups from HLPB, as well as of water diffusion taking place in amorphous regions, enhanced the crosslink density, leading to higher modulus.

Regarding to thermal degradation (Table 5 and Figure 8), an increase of $\mathrm{T}_{\text {onset }}$ was observed with grafting of pure Ziegler-Natta LLDPE (BF0) and, in presence of HLPB, this increase was even higher, what can be directly related to the gel content of these samples. Thus, it can was confirmed that the higher the gel content, the higher $\mathrm{T}_{\text {onset }}$ was found ${ }^{19,28}$. Likewise, the maximum degradation temperature $\left(\mathrm{T}_{\max }\right)$ of BPB10 sample (PEX + HLPB) was higher among these materials and mass loss was the lowest found.

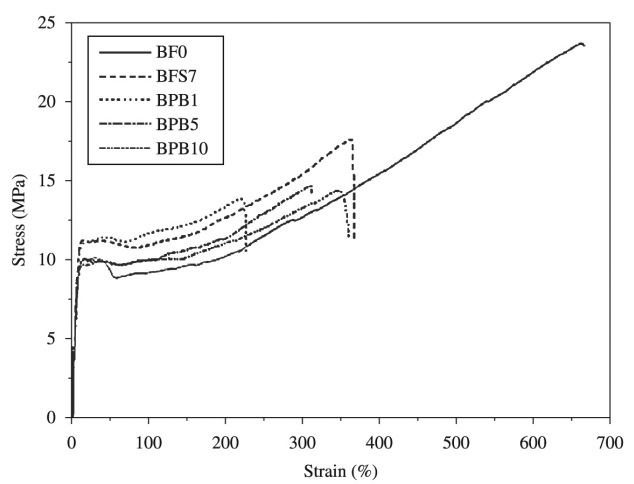

Figure 7. Stress-strain curves of the crosslinked samples. 
Table 4. Mechanical properties of crosslinked samples.

\begin{tabular}{cccccc}
\hline Sample & $\begin{array}{c}\text { Tensile Stress at } \\
\text { Yield }(\mathbf{M P a})\end{array}$ & $\begin{array}{c}\text { Elongation at Yield } \\
\mathbf{( \% )}\end{array}$ & Modulus (MPa) & $\begin{array}{c}\text { Tensile Stress at } \\
\text { Break (MPa) }\end{array}$ & $\begin{array}{c}\text { Elongation at Break } \\
\mathbf{( \% )}\end{array}$ \\
\hline BF0 & $10.78 \pm 0.63$ & $29.13 \pm 0.99$ & $149.79 \pm 13.20$ & $22.50 \pm 2.72$ & $621.32 \pm 79.76$ \\
BFS7 & $11.47 \pm 0.77$ & $21.65 \pm 10.9$ & $194.75 \pm 31.06$ & $16.61 \pm 1.26$ & $326.64 \pm 47.29$ \\
BPB1 & $11.09 \pm 0.61$ & $44.29 \pm 2.87$ & $126.12 \pm 15.42$ & $14.13 \pm 1.69$ & $246.46 \pm 46.92$ \\
BPB5 & $11.07 \pm 0.80$ & $43.17 \pm 7.05$ & $127.41 \pm 22.90$ & $13.78 \pm 2.55$ & $220.14 \pm 133.97$ \\
BPB10 & $11.03 \pm 0.79$ & $22.24 \pm 10.4$ & $180.93 \pm 23.53$ & $13.66 \pm 1.85$ & $233.66 \pm 122.15$ \\
\hline
\end{tabular}

$\mathrm{BF} 0=\mathrm{HDPE}, \mathrm{ZN}$; BFS7 $=$ HDPE with $2.5 \%$ of VTMS; BPB 1,5 and $10=\mathrm{BFS} 7$ with 1 to $10 \% \mathrm{w} / \mathrm{w}$ of HLPB.

Table 5. Thermal properties of PEX's samples.

\begin{tabular}{cccc}
\hline Sample & $\mathbf{T}_{\text {onset }}\left({ }^{\circ} \mathbf{C}\right)$ & $\mathbf{T}_{\max }\left({ }^{\circ} \mathbf{C}\right)$ & Total Loss $(\%)$ \\
\hline BF0 & 424.4 & 458.1 & 99.5 \\
BFS7 & 434.5 & 463.6 & 98.4 \\
BPB10 & 444.2 & 469.7 & 98.2 \\
\hline
\end{tabular}

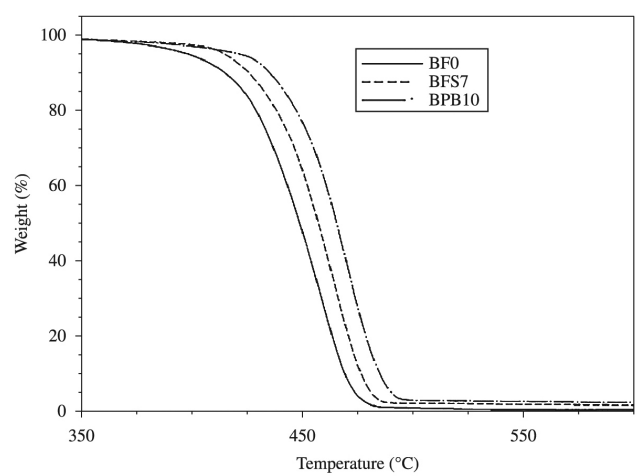

Figure 8. Profiles of thermogravimetric analysis of the crosslinked samples.

\section{Conclusions}

The silane method employed in the synthesis of PEX starting from various grades of polyethylene under the conditions studied proved to be feasible, as shown by increasing of gel content of polyethylenes studied, the most important parameter. Several variables were investigated: starting polymer, influence of comonomer, catalyst-type and crosslinking coagent. The Ziegler-Natta LLDPE with butene resulted in better performance of crosslinking compared

\section{References}

1. Atkinson JR and Cicek RZ. Silane cross-linked polyethylene for prosthetic applications. Part I. Certain physical and mechanical properties related to the nature of the material. Biomaterials. 1983; 4(4):267-275. http://dx.doi.org/10.1016/0142-9612(83)90026-1. PMid:6640052

2. Morshedian J and Hoseinpour PM. Polyethylene crosslinking by two-step silane method: a review. Iranian Polymer Journal. 2009; 18(2):103-128.

3. Melo RP and Marques MFV. PEX synthesized via peroxide for oil pipes, starting from different commercial polyethylenes: influence of comonomer and catalyst type. Macromolecular Symposia. 2011;299-300(1):246-253. http://dx.doi.org/10.1002/ masy.200900139. to the Ziegler-Natta LLDPE with hexene due to the lower length of ethylene sequences in this polymer microstructure. Comparing with the metallocene LLDPE, its crosslinking performance was lower than the ZN LLDPE due to the virtual absence of extractable fractions containing low MW and high comonomer content. Among the employed PE, HDPE was the lowest crosslinking content due to the low amount of tertiary carbons in the chain and high crystalline degree. The PEX formed from HDPE with a crosslinking coagent (hydroxylated liquid polybutadiene) showed gel content 3 times higher when it was incorporated $10.0 \%$ HLPB, due to addition of the coagent crosslinking at same time with silane and catalyst, increasing the distance between the linear chains, reducing crystallinity of grafted material. Increasing the concentration of HLPB on PEX led to an improved resistance to thermal degradation and this behavior is related to the higher gel content of these samples. And finally, incorporation of HLPB in PEX improved elastic modulus mainly at $10.0 \mathrm{wt} . \%$ of crosslinking coagent.

This research field is highly interesting and should keep going. Some additional work may be suggested. Rheology, as well as dynamic-mechanical analysis, can be performed on crosslinked polyethylenes. Moreover, incorporation of HLPB at different contents on silane-crosslinked metallocene LLDPE could be also tested. And, finally, inorganic fillers can be added to polyethylene during crosslinking reactions (by peroxide or silane) and, consequently, mechanical and thermal properties may be studied.

\section{Acknowledgements}

We thank the National Research Council (CNPq) for financial support and Braskem for supplying supply of polymers used in the experiments.

4. Song Y, Wu S, Jing X, Sun J and Chen D. Thermal, mechanical and ionic conductive behaviour of gamma-radiation induced $\mathrm{PEO} / \mathrm{PVDF}(\mathrm{SIN})-\mathrm{LiClO} 4$ polymer electrolyte system. Radiation Physics and Chemistry. 1997; 49(5):541-546. http://dx.doi. org/10.1016/S0969-806X(96)00158-2.

5. Oliveira GL and Costa MR. Optimization of process conditions, characterization and mechanical properties of silane crosslinked high-density polyethylene. Materials Science and Engineering. 2010; 527(18-19):4593-4599. http://dx.doi.org/10.1016/j. msea.2010.03.102.

6. Hirabayashi H, Iguchi A, Yamada K, Nishimura H, Ikawa K and Honma H. Study on the structure of peroxide cross-linked polyethylene pipes with several stabilizers. Materials Sciences and Applications. 2013; 4(9):497-503. 
7. Barzin J, Azizi H and Morshedian J. Preparation of silane-grafted and moisture crosslinked low density polyethylene. Part II: electrical, thermal and mechanical Properties. Polymer-Plastics Technology and Engineering. 2007; 46(3):305-310. http:// dx.doi.org/10.1080/03602550601155815.

8. Ramos VD, Costa HM, Pereira AO, Rocha MCG and Gomes AS. Study of low concentrations of dicumyl peroxide on the molecular structure modification of LLDPE by reactive extrusion. Polymer Testing. 2004; 23(8):949-955. http://dx.doi. org/10.1016/j.polymertesting.2004.04.012.

9. Svoboda P, Poongavalappil S, Theravalappil R, Svobodova D and Mokrejs P. Effect of octene content on peroxide crosslinking of ethylene-octene copolymers. Polymer International. 2013; 62(2):184-189. http://dx.doi.org/10.1002/pi.4277.

10. Kircher K. Chemical reactions in plastics processing. Munich: Carl Hanser Verlag GmbH \& Co; 1988.

11. Campus A and Mateu G. Influence of temperature on the properties of crosslinked LDPE. Wire Journal International. 1985; 18(5):57-62.

12. Jiao $\mathrm{C}$, Wang $\mathrm{Z}$, Liang $\mathrm{X}$ and $\mathrm{Hu}$ Y. Non-isothermal crystallization kinetics of silane crosslinked polyethylene. Polymer Testing. 2005; 24(1):71-80. http://dx.doi.org/10.1016/j. polymertesting.2004.07.007.

13. Liu NC, Yao GP and Huang H. Influences of grafting formulations and processing conditions on properties of silane grafted moisture crosslinked polypropylenes. Polymer. 2000; 41(12):4537-4542. http://dx.doi.org/10.1016/S0032-3861(99)00654-0.

14. Bengtsson M and Oksman K. The use of silane technology in crosslinking polyethylene/wood flour composites. Composites Part A: Applied Science and Manufacturing. 2005; 37(5):752765.

15. Marcilla A, Ruiz-Femenia R, Hernández J and García-Quesada JC. Thermal and catalytic pyrolysis of crosslinked polyethylene. Journal of Analytical and Applied Pyrolysis. 2006; 76(1-2):254259. http://dx.doi.org/10.1016/j.jaap.2005.12.004.

16. Celina $\mathrm{M}$ and George GA. Characterization and degration studies of peroxide and silane crosslinked polyethylene. Polymer Degradation \& Stability. 1995; 48(2):297-312. http://dx.doi. org/10.1016/0141-3910(95)00053-O.

17. Whelton A, Dietrich A and Gallagher D. Contaminant diffusion, solubility, and material property differences between HDPE and PEX potable water pipes. Journal of Environmental Engineering. 2010; 136(2):227-237. http://dx.doi.org/10.1061/ (ASCE)EE.1943-7870.0000147.
18. Shah GB, Fuzail M and Anwar J. Aspects of the crosslinking of polyethylene with vinyl silane. Journal of Applied Polymer Science. 2004; 92(6):3796-3803. http://dx.doi.org/10.1002/ app.20381.

19. Wang Z, Hu Y, Gui Z and Zong R. Halogen-free flame retardation and silane crosslinking of polyethylenes. Polymer Testing. 2003; 22(5):533-538. http://dx.doi.org/10.1016/S0142-9418(02)00149-6.

20. Sirisinha K, Boonkongkaew M and Kositchaiyong S. The effect of silane carriers on silane grafting of high-density polyethylene and properties of crosslinked products. Polymer Testing. 2010; 29(8):958-965. http://dx.doi.org/10.1016/j. polymertesting.2010.08.004.

21. Marcilla A, García-Quesada JC, Hernández J, Ruiz-Femenia $\mathrm{R}$ and Perez JM. Study of polyethylene crosslinking with polybutadiene as coagent. Polymer Testing. 2005; 24(7):925931. http://dx.doi.org/10.1016/j.polymertesting.2005.06.002.

22. Sirisinha $\mathrm{K}$ and Chimdist $\mathrm{S}$. Comparison of techniques for determining crosslinking in silane-water crosslinked materials. Polymer Testing. 2006; 25(4):518-526. http://dx.doi.org/10.1016/j. polymertesting.2006.01.015.

23. Jiao $\mathrm{C}$, Wang $\mathrm{Z}$, Gui $\mathrm{Z}$ and $\mathrm{Hu}$ Y. Silane grafting and crosslinking of ethylene-octene copolymer. European Polymer Journal. 2005; 41(6):1204-1211. http://dx.doi.org/10.1016/j. eurpolymj.2004.12.008.

24. Zhang G, Wang G, Zhang J, Wei P and Jiang P. Performance evaluation of silane crosslinking of metallocene-based polyethylene-octene elastomer. Journal of Applied Polymer Science. 2006; 102(5):5057-5061. http://dx.doi.org/10.1002/ app. 25169 .

25. Wong WK and Varrall DC. Role of molecular structure on the silane crosslinking of polyethylene: the importance of resin molecular structure change during silane grafting. Polymer. 1994; 25:5449.

26. Khonakdar HA, Morshedian J, Wagenknecht U and Jafari SH. An investigation of chemical crosslinking effects on properties of high-density polyethylene. Polymer. 2003; 44(15):4301-4309. http://dx.doi.org/10.1016/S0032-3861(03)00363-X.

27. Yussuf AA, Kosior E and Alban L. Silane grafting and crosslinking of metallocene-catalysed LLDPE and LDPE. Malaysian Polymer Journal. 2007; 2:58-71.

28. Oliveira GL and Costa MF. Optimization of process conditions, characterization and mechanical properties of silane crosslinked high-density polyethylene. Materials Science and Engineering A. 2010; 527(18-19):4593-4599. http://dx.doi.org/10.1016/j. msea.2010.03.102. 